\title{
A Multitarget Land Use Change Simulation Model Based on Cellular Automata and Its Application
}

\author{
Jun Yang, ${ }^{1,2}$ Fei Chen, ${ }^{1}$ Jianchao Xi, ${ }^{2}$ Peng Xie, ${ }^{1}$ and Chuang $\mathrm{Li}^{1}$ \\ ${ }^{1}$ Liaoning Key Laboratory of Physical Geography and Geomatics, Liaoning Normal University, Dalian 116029, China \\ ${ }^{2}$ Institute of Geographic Sciences and Natural Resources Research, CAS, Beijing 100101, China \\ Correspondence should be addressed to Jun Yang; yangjun@lnnu.edu.cn
}

Received 17 April 2014; Accepted 1 June 2014; Published 29 June 2014

Academic Editor: Jianzhou Wang

Copyright (c) 2014 Jun Yang et al. This is an open access article distributed under the Creative Commons Attribution License, which permits unrestricted use, distribution, and reproduction in any medium, provided the original work is properly cited.

\begin{abstract}
Based on the analysis of the existing land use change simulation model, combined with macroland use change driving factors and microlocal land use competition, and through the application of Python language integrated technical approaches such as CA, GIS, AHP, and Markov, a multitarget land use change simulation model based on cellular automata(CA) is established. This model was applied to conduct scenario simulation of land use/cover change of the Jinzhou New District, based on 1:10000 map scale land use, planning, topography, statistics, and other data collected in the year of 1988, 2003, and 2012. The simulation results indicate the following: (1) this model can simulate the mutual transformation of multiple land use types in a relatively satisfactory way; it takes land use system as a whole and simultaneously takes the land use demand in the macrolevel and the land use suitability in the local scale into account; and (2) the simulation accuracy of the model reaches $72 \%$, presenting higher creditability. The model is capable of providing auxiliary decision-making support for coastal regions with the analysis of the land use change driving mechanism, prediction of land use change tendencies, and establishment of land resource sustainable utilization policies.
\end{abstract}

\section{Introduction}

Land use change refers to a complicated change caused by the interaction of natural and social systems in different temporal and spatial scales [1]. As a typical reflection of LUCC in terms of land use layout structure, land use change involves not only natural factors such as soil, water, and atmosphere, but also social factors including government policies, economy, population, and values. Land use change plays an important role in ecological systems, global environmental changes, and sustainable development. With the development of society and growth of population, the contradictions among population, resources, and environment have become increasingly severe, and people are also paying growing attention to research on land use change $[2,3]$. In addition, with China's rapidly growing economy, the country is currently experiencing a period dominated by the great transformation of social and economic structures, which result in deeper changes faced by land use in China.

The land use change simulation model can reveal the causes of temporal and spatial changes of land use, driving mechanism of impact factors, and acting approaches. It can also provide a decision-making basis for the prediction of future development and changing trends and the establishment of relevant policies [4]. Throughout the world, the model currently includes the following several relatively representative land use change simulation and prediction models: the conversion of land use and its effects at small regional extent (CLUE-S), system dynamics (SD), Markov model, multiagent system (MAS), cellular automata (CA).

The CLUE-S model was built by Verburg et al., based on the CLUE model and high-resolution spatial graphic data. Although it has a relatively strong capacity to simulate land use scenario patterns of different scales, the model mainly takes statistical and empirical models as the basis for the evolution and distribution of local land use patterns. As a result, it is difficult for this model to fully reflect the complicated characteristics of the evolution of microcosmic pattern of land use $[5,6]$. SD can reflect the complicated behaviors of land systems in macroterms and boasts long-degree simulation characteristics and the advantage of scenario simulation. However, as a top-to-bottom macroquantitative model, clear 
shortcomings still exist in this model, in respect to the reflection of spatial pattern characteristics of land use $[7,8]$. The Markov model is capable of predicting change in quantity of land use types, and the area proportion of each land use type in the future can be precisely predicted using this model. However, it cannot be used to determine its spatial position or the characteristics of spatial change and distribution [9]. The MAS model generates a macroglobal pattern through the interaction of microindividuals, mainly based on a bottomto-top mathematical modeling concept. It has outstanding characteristics in terms of its flexible setting and strong applicability concerning the simulation of dynamic changes of temporal and spatial changes of land use. However, the model's decision-making framework must be further perfected and its inspection and verification methods require further exploration [10]. Nevertheless, land use change is a result of nonlinear complicated and comprehensive actions of humanistic and natural factors in different scales. Thus, it is still a great challenge for land use change simulation models to fully reflect the macrodriving factors of land use system change and the complicated characteristics of the evolution process of microcosmic patterns, as well as to improve the reliability of land use change simulation [11].

Cellular automata (CA) was first proposed by Ulan and Von Neumann in the late 1940s. It is a grid dynamical model in which time, space, and state are all discrete, and spatial interaction and temporal casual relationship are both local, and it is able to simulate the temporal and spatial evolution process of complicated systems [12]. The parts constituting CA are called as "cells," and each cell has a state which can only be a concentrated finite state. The states of the cells change with time and are determined according to local transition rules [13]. Wolfram proved that the CA model could simulate complicated natural phenomena and established the basis of CA theory. CA is defined as a discrete dynamical model which can evolve a global change pattern in terms of time and space, through local behaviors among individuals $[14,15]$. For these reasons, CA has been widely applied in LUCC $[16,17]$, urban growth [18, 19], fire [20,21], ecology [22, 23], traffic flow $[24,25]$, and simulation in other relevant areas.

CA also adopts a bottom-to-top modeling concept with strong spatial modeling and computing capacity and is thus able to effectively simulate spatial changes of systems, but it mainly focuses on the interaction of the local neighborhood of cells. During the simulation process, it emphasizes the elements of the natural environment. However, it fails to consider complicated spatial decision-making behaviors and humanistic factors, thus presenting certain limitations. During LUCC simulation, in order to more effectively match CA with the research subject, many limiting conditions of CA model must be solved in a proper manner, and macroimpact factors such as society and economy must be taken into account so as to combine CA with other models and techniques. Li and Yeh have put forward a CA model based on artificial neural networks [26] and ant colony algorithm [27] and conducted simulation for the Pearl River Delta region on multiple times. Breakthroughs have also been obtained in the research of automatic extraction of cell transition rules using artificial intelligence technology. Lauf et al. researched an improved CA model, which discusses the expansion of residential construction land with $\mathrm{SD}$ as the basis and family and housing factors as the driving forces. Furthermore, it has been pointed out that population mobility and change of age structure are currently two important reasons for either the urban growth or shrinking of European countries and USA [28]. Arsanjani et al. combined the Markov model, logistic regression model, and CA model, thus enormously improving the accuracy rate of the simulation of urban expansion [18].

Domestic and foreign experts and scholars have performed abundant research regarding the simulation and prediction of land use change, but we must also be aware of the following problems existing in the research of the driving mechanism and simulation of land use change and which urgently require solutions: the research on driving force generated by the interaction between macrofactors and regional land use types on the land use change is insufficient; although there has been relatively abundant research on the one-way transformation from nonurban land use types to urban land use types during simulation of land use change, research on mutual transformation among multiple land use types and multitarget land use type simulation is insufficient; in addition, research on the inner mechanism in which oceanic impact factors in coastal regions influence land use spatial pattern is also insufficient. If viewed from these aspects, new models and methods of long term and large scale are employed to conduct research on LUCC simulation and prediction of coastal regions, which is of great theoretic and realistic significance for the exploration of the reasonable utilization of land resources, orderly expansion of urban space, and development and protection of cultivated land and unused land under the background of new urbanization. This is also an important research topic for realizing the harmonic development of the human race and the environment and the sustainable development of human society.

In summary, based on technical approaches such as CA, GIS, AHP, and Markov, the present study comprehensively considers the influence of macrodriving factors and local land use competition on land use change, establishes a multitarget land use change model based on CA, studies the land use change simulation of the Jinzhou New District of Dalian City, and verifies the reliability of the model, so as to provide model support and empirical study of multitarget land use change simulation.

\section{Multitarget Land Use Change Simulation Model Based on Cellular Automata}

The theoretic precondition of the multitarget land use change simulation model based cellular automata is that the land use change is mainly driven by the land macrodemand of this region and the interaction among microlocal neighborhoods, and there are phenomena of mutual conversion among each land use type in land use change. The entire model mainly consists of CA, GIS, AHP, and Markov and is implemented by the method of loose integration. The CA module is implemented through Python language programming, and 


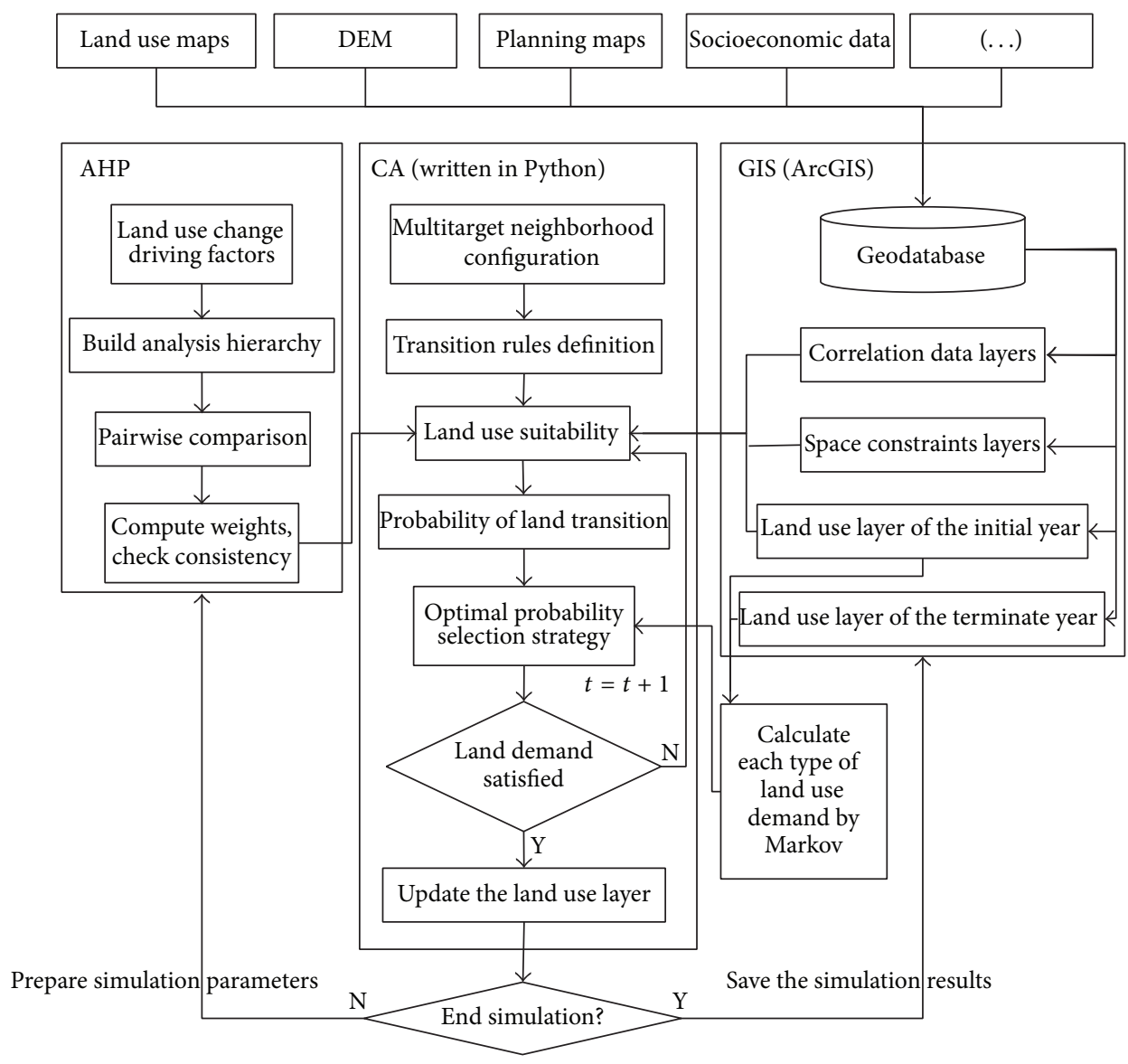

FIGURE 1: Flowchart of multitarget land use change simulation model based on cellular automata.

the GIS spatial analysis module is completed by relying on the ArcGIS Desktop of ESRI. The CA model and GIS adopt tightly integrated models, and Python language is adopted to call the ArcGIS Raster module function to implement the CA model. The change of area of each land use type is calculated and simulated from the initial year to the terminate year through the Markov model, so as to acquire the total demand of land use. The weights of the indexes which influence land use suitability are calculated by AHP. The optimum probability selection strategy is adopted to conduct the dynamic simulation of spatial configuration of land use until the demand has been satisfied. The flow chart of the multitarget land use change simulation model based on CA is shown in Figure 1.

The main technique process of this study is as follows: GIS can provide abundant spatial information and a powerful spatial data processing platform for land use change simulation. GIS is then applied to process land use data, basic elements data, topographic data, and planning data to obtain a comprehensive geographic information database with consistent data structures and unified geographic coordinates. The massive spatial information provided by GIS may be used as various spatial variables and restrictions required for CA input. In addition, the powerful spatial analysis function of GIS can be utilized to obtain the layer required for evaluation of land use suitability. The transition rules of the model are often expressed by transition probability or transition potential. Based on macro- and microfactors influencing land use change, the AHP decision-making analysis method is applied to acquire the weight parameters of different impact factors driving land use change, so as to obtain the land use suitability, after which it can be transited to the multitarget transition probability through a certain algorithm. In this model, the Markov prediction method is mainly used to calculate the change of area of each land use type from the initial year to the terminate year of simulation. In the CA model, based on the defining neighborhood and transition rules, various parameters mentioned above and optimum probability selection strategy are utilized to judge the changes of cell land use types one by one on the basis of the input of land use map until all land use demands have been satisfied. Then, the spatial iterative process is ended and a new land use simulation layer of the targeted year is obtained.

2.1. Multitarget Land Use Change. Land use change process involves the mutual transition among multiple land use types. Spatial autocorrelation exists when a value observed in one geographic location relies on the values of neighboring locations. Spatial autocorrelation relationship exists in the geographic study object, and this kind of relation can not only function among plots of the same land use type, but also play 


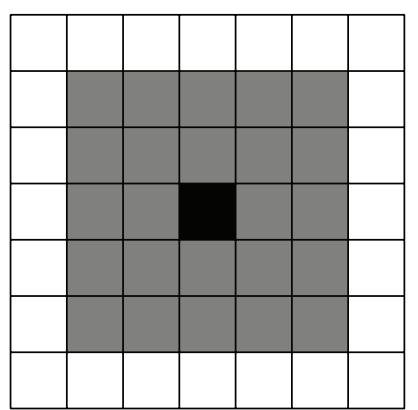

FIGURE 2: Moore neighborhood $(r=2)$.

a part in plots of different land use types. Before implementing the multitarget land use change simulation model based on CA, we have to study the function relationship between the initial land use type and terminate land use type of the central cell under different neighborhood scenarios. These requires the quantity of cells of each land use type within the cell neighborhood as the neighborhood scenario, the initial land use type of the central cell as the input variable and the terminate land use type of the central cell simulated as the output variable. The interaction between land use type of the central cell and land use type of the neighborhood cell is usually equivalent during calculation [29], which has simplified the computation complicacy. However, this also covered the issue of acting direction of land use type, as the transition of land use type of central cell is based on independent neighborhood scenario. Therefore, the influence relation among land use types is that of nonequivalence.

During land use change, the cell states mainly refer to the different current situations of land use, for example, agricultural land, construction land, and unused land. The neighborhood structure of cell determines its transition state; that is, the closer to the central cell, the greater the effect on the state transition in the transition rules. Moore neighborhood is adopted as the neighborhood structure of cell in this model. Radius of neighborhood $r=2$ (i.e., $5 * 5$ neighborhoods, as shown in Figure 2).

Three land use types with large area proportion and obvious change, namely, agricultural land (A), construction land (B), and unused land (U), are selected as the study objects in this model to study the competitive relation of cells in the neighborhood and multitarget land use change. Water area (S) with small change in area and stable position is selected as the protective land and, during the simulation process, cells of this type do not go through land use type transition. Furthermore, other cells do not transit to this land use type either. Different land use type cells are indicated by different colors. As shown in Figure 3, the initial land use type of the central cell is agricultural land; the number of cells of agricultural land in the neighborhood scenario is 7 (Num (A) $=7$ ); the number of cells of construction land is 8 (Num (B) $=8)$; the number of cells of unused land is $7(\operatorname{Num}(U)=7)$. The probabilities of the final land use type of the central cell as agricultural land, construction land, or unused land are different under the influence of the neighborhood scenario.

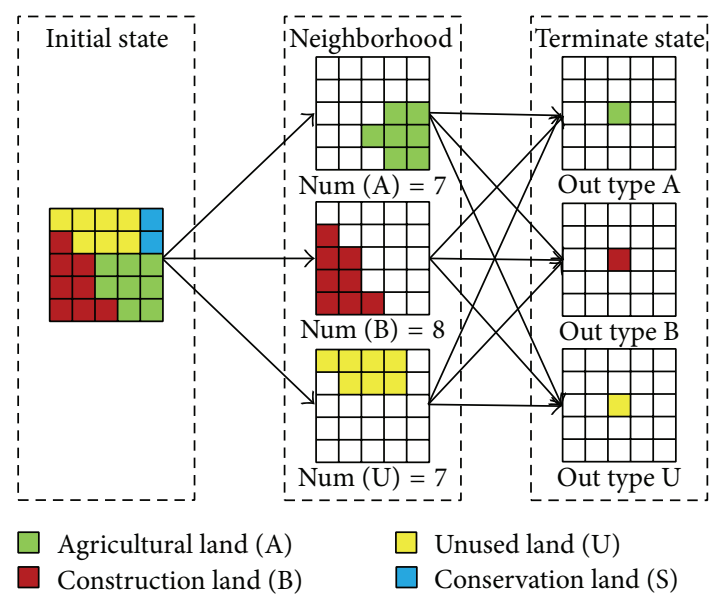

FIGURE 3: Multitarget land use change in neighborhood.

The initial land use condition of each cell will be known during land use change simulation, and some training data will be available in order to establish a model which can reflect the true land use evolution. Such training data can be used to calibrate and verify the land use change simulation model [13]. According to the development of the study area and the continuity of land use change, two periods of land use data are adopted in the model correction stage to calculate the multitarget transition probability of the land use type of the central cell under each neighborhood scenario. The calculation method is shown as follows.

First, we can record a land use change process as Trans:

$$
\operatorname{Trans}\left(S_{i} \longrightarrow S_{j} \mid S_{k}=n\right) \text {, }
$$

where $S_{i} \rightarrow S_{j}$ indicates the transition state of the central cell from $S_{i}$ to $S_{j}$, and $S_{k}=n$ indicates a neighborhood scenario in which the quantity of cells with state of $S_{k}$ in the neighborhood is $n$.

The initial land use types, terminate land use types, and neighborhood scenarios of all of the cells calculated in the research area are indicated as follows:

$$
\operatorname{Count}\left(S_{i} \longrightarrow S_{j} \mid S_{k}=n\right) \text {. }
$$

This formula indicates that the quantity of cases of cells with state of $S_{k}$ under the neighborhood scenario within the neighborhood is $n$ and with central cell transited from $S_{i}$ to $S_{j}$. It can further indicate the potential of transition of the central cell from land use type $i$ to $j$ when the quantity of cells with state of $S_{k}$ within the scope of the neighborhood is as follows:

$$
P\left(S_{i} \longrightarrow S_{j} S_{k}=n\right)=\frac{\operatorname{Count}\left(S_{i} \longrightarrow S_{j} S_{k}=n\right)}{\operatorname{Count}\left(S_{i} S_{k}=n\right)} .
$$

Based on the different values of $n$, the transition potential is indicated by the following set:

$$
C_{i \rightarrow j \mid k}=\left\{P\left(S_{i} \longrightarrow S_{j} \mid S_{k}=n\right) \mid n \in[0, \eta]\right\},
$$

where $\eta$ indicates the sum of cell quantities within the neighborhood except central cell ( $\eta=24$ in this model). 
The potential of transition state of the central cell containing all neighborhood scenarios from $S_{i}$ to $S_{j}$ is indicated through the following formula:

$$
I_{i \rightarrow j}=\sum_{k}^{m} C_{i \rightarrow j \mid k}
$$

where $m$ indicates the quantity of cell state within this neighborhood.

Therefore, the local land use type state transition potential matrix can be expressed as follows:

$$
\begin{gathered}
\pi_{i}=\left|\begin{array}{cccc}
I_{i \rightarrow i} & I_{i \rightarrow j} & \cdots & I_{i \rightarrow m}
\end{array}\right|, \\
\pi=\left|\begin{array}{cccc}
I_{i \rightarrow i} & I_{i \rightarrow j} & \cdots & I_{i \rightarrow m} \\
I_{j \rightarrow i} & I_{j \rightarrow j} & \cdots & I_{j \rightarrow m} \\
\vdots & \vdots & \vdots & \vdots \\
I_{m \rightarrow i} & I_{m \rightarrow j} & \cdots & I_{m \rightarrow m}
\end{array}\right| .
\end{gathered}
$$

It is worth noting that the transition potential indicates the degree of competitive advantage of the central cell when going through such type of change. Therefore, the sum of all values in $\pi_{i}$ is not equal to 1 .

2.2. Transition Rules and Comprehensive Transition Probability. The core part of CA is the definition of the transition rules. The state transition of a cell from moment $t$ to moment $t+1$ is decided by the states of itself and its neighbors at moment $t$, as well as the relevant transition rules. The transition rules of CA are reflected by the expression of the neighborhood function. During the simulation process, it is required to conduct dynamic iterative computation of the change of neighborhood. The function expression is shown as follows:

$$
S_{i j}^{t+1}=f\left(S_{i j}^{t}, \Omega_{i j}^{t}, T^{t}\right),
$$

where $S_{i j}^{t+1}$ and $S_{i j}^{t}$ indicate the land use states of cell $i j$ at moment $t+1$ and moment $t$, respectively; $\Omega_{i j}^{t}$ indicates the development condition of the neighborhood space of cell $i j$ (representing the neighborhood effect); $T^{t}$ refers to a series of transition rules; and $f$ refers to the state transition function. The formula indicates that land use change is a history dependent process, as the past land use state influences future land use through interaction among plots. In the simulation, the interaction among local neighborhood cells is captured through a movable $5 * 5$ window which will be applied to each pixel and return a value to indicate the ratio of state $S_{i j}^{t}$ among its 24 neighbors. Such local and dynamic information is reflected through a series of impact factors. We then utilize the weighing and addition of the evaluation score of impact factors and transit it to the probability of cell $i j$ at moment $t+1$.

If analyzed from the perspective whether factors influencing land use change alter during the land use change process, the impact factors of land use change can be classified as either dynamic factors or static factors. Dynamic factors continuously change during the entire simulation process and reflect the results of transition state of cells in each iterative process. If the cell state within the scope of the neighborhood changes, then the transition potential matrix will be updated accordingly. Static factors remain as constants throughout the entire simulation process and reflect the global configuration of cell space, for example, spatial distance from the urban center. Static and dynamic factors impose different influences on the land use change simulation, which are mainly reflected by the respective weights of different factors.

Land use change process is very complicated. Besides the action of the local neighborhood (dynamic factor), a suitable condition (static factor) also plays a very important role in the transition of land use types. Therefore, in this model a land use suitability layer $L$, corresponding to each land use type, has been built:

$$
L_{i}=\left(\sum_{k=1}^{\alpha} F_{i k} W_{i k}\right) \prod_{k=1}^{\beta} F_{i k},
$$

where $F_{i k}$ refers to the scoring of impact factor $k$ to class $i$ land use type. When $1<k<\alpha, F_{i k}$ indicates a nonrestrictive suitable condition composed of a group of spatial distance variables; when $1 \leq k \leq \beta, F_{i k}$ indicates restrictive suitable condition composed of protective land, topography, and so forth, and the value of this score is either 0 or $1 . W_{i k}$ indicates the weight of nonrestrictive suitable condition $k$ for class $i$ land use type and is acquired by using AHP. During each simulation process, the comprehensive transition probability of land use type of each cell is obtained based on the transition potential of the land use type generated through the interaction of local neighborhood land use types and the suitability of land use. It can be indicated as follows:

$$
p_{i j}=\exp \left[\alpha\left(\frac{\pi_{i} \times L_{j}}{\max \left(\pi_{i} \times L_{j}\right)}-1\right)\right],
$$

where $p_{i j}$ indicates probability of transition from class $i$ land use type to class $j$ land use type, and $\alpha$ indicates the variable of discrete degree with the value determined as $0-1$. Since the states of the neighborhood cells are dynamic, the comprehensive transition probability is also dynamic. As a result, the transition rules of the CA model in each time step length are updated.

2.3. Acquisition of Weights. In land suitability evaluation, the setting of weights of different factors must be considered based on various different evaluation factors. How to set these weights is essential, and weights can be acquired through expert scoring by utilizing AHP [30]. AHP acquires priority from the comparison of application coupling (degrading from general criterion to secondary criterion). It is only required to compare a couple of criteria before making an effective decision. A 9-point scale can be applied in the comparison to measure the priority of a couple of criteria. Matrix $A$ is determined as follows:

$$
A=a_{i j}=\frac{w_{i}}{w_{j}},
$$


where $W=\left(w_{i}\right)^{T}$ refers to the feature vector of matrix $A$ and $w_{i}$ indicates the weight of vector $W$ which is distributed from 1 to 9; meanwhile, $a_{i j}$ is distributed from $1 / 9$ to 9 . When the main feature vector $a_{i j}$ is normalized, the priority of the decision maker has been reflected and is described as follows:

$$
A W=\left(\frac{\omega_{i}}{\omega_{j}}\right) *\left(\omega_{i}\right)^{T}=\lambda^{\max } W
$$

where $\lambda^{\max }$ refers to the maximum eigenvalue of matrix $A$. Consistency index

$$
\mathrm{CI}=\frac{\lambda^{\mathrm{max}}-n}{n-1}
$$

When $\mathrm{CI}=0$, the matrix is judged as fully consistent; on the contrary, the greater the $\mathrm{CI}$ is, the poorer the judgment of the matrix consistency will become.

\subsection{Optimum Probability Selection Strategy. CA simulation} is completed by several loops. In order to express the uncertainty of the land evolution, the optimum probability selection strategy is adopted in each loop to determine if this cell has gone through state transition. In order to define whether or not transition of land use type occurs to the cell, it is necessary to introduce a threshold to indicate the resistance of the transition of land use type. When the comprehensive transition probability of the cell is greater than this threshold, the cell land use type transits [31]. The transition potential of each cell to different land use types can be calculated during each iterative process of the multitarget land use change simulation model based on CA. If a unified threshold is used to uniformly process all cells, then the condition that a cell is transited toward multiple directions will present itself. If these data are recorded one by one, a very large quantity of simulation results is certain to be generated, which is not permitted by either the algorithm efficiency or computer storage space. By referring to the CA-Markov model, the optimum probability selection strategy is adopted in this model to judge the change of land use type of cells one by one, based on the initial land use map input. The cell with the maximum comprehensive transition probability will be selected with priority to pass through transition, so as to judge the transition direction of the cells from an overall perspective, until all land use demands have been satisfied. Then, the spatial iterative process is concluded to obtain a new land use simulation layer in the targeted year (as shown in Figure 4).

\section{Case Application and Results}

3.1. Overview of Study Area and Data Sources. The Jinzhou New District of Dalian is located in the southern area of the Liaodong Peninsula and the middle of Dalian, with coordinates of $121^{\circ} 26^{\prime}-122^{\circ} 18^{\prime} \mathrm{E}$ and $38^{\circ} 56^{\prime}-39^{\circ} 24^{\prime} \mathrm{N}$. It faces the Yellow Sea on the east and approaches the Bohai Sea on the west. The isthmus separates Jinzhou Bay and Dalian Bay. The district borders on the Ganjingzi District of Dalian to the south and connects with Pulandian to the north.

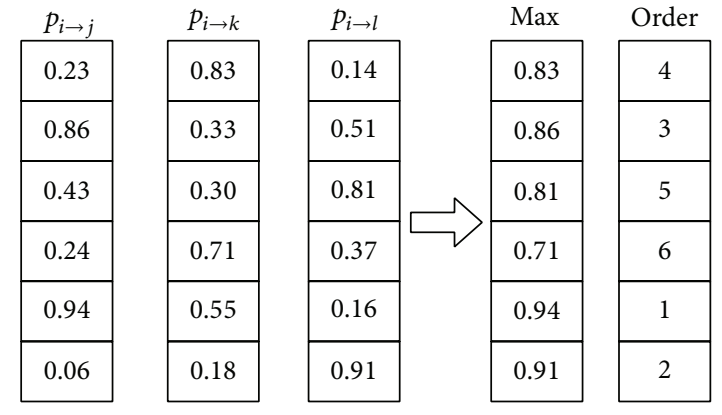

FIGURE 4: Sketch of the optimal probability selection strategy.

Separated from Wafangdian by sea, the district grips the throat of Dalian (as shown in Figure 5). The district covers a total area of $1,483.22 \mathrm{~km}^{2}$. The favorable geographical location advantages and national policies have enabled Jinzhou New District to realize rapid economic and social development and continuous improvement of urbanization level over the past twenty years. At the same time, the demands for land resources, especially construction land, have significantly increased; the spatial pattern of land use has changed rapidly; the difference of internal structure has become obvious; and the contradictions between men and land have become increasingly prominent. Therefore, it is typical and representative to use the Jinzhou New District as an empirical case in the land use change study of coastal regions.

Multidate land usage and cover data is adopted in the model for simulation. The research data of this paper is mainly obtained from the 1:10000 map scale vector land use database of 1988, 2003, and 2012, provided by the Dalian Municipal Bureau of Land Resources and Housing. These data comply with the Present Status Classification of Land Utilization (GB/T 21010-2007) of the People's Republic of China. The topographic data is obtained from the International Scientific Data Mirror Site of Computer Network Information Center, China Academy of Sciences (http://www.gscloud.cn) (detailed in Table 1).

In order to simplify the simulation process, according to the "PRC Law on Land Management," the land use types are classified into agricultural land (A), construction land (B), and unused land (U). Meanwhile, the rivers, reservoirs, intertidal zones, and so forth are extracted as conservation land (S) prohibited for change, as well as restrictive layer (specific classification shown in Table 2), since they are protected in the land use planning.

3.2. Driving Factors and Setting of Model Parameters. In land use change simulation, land use/land cover changes dynamically. A series of natural and social factors drive land use change. Before the model is used for formal simulation, it is required to set and continuously correct the parameters, in order to ensure smooth simulation, as well as to guarantee the accuracy of the simulation result. The model parameters mainly consist of two parts: weights of driving factors and land use transition probability matrix. Driving factors here mainly refer to static factors influencing land use 


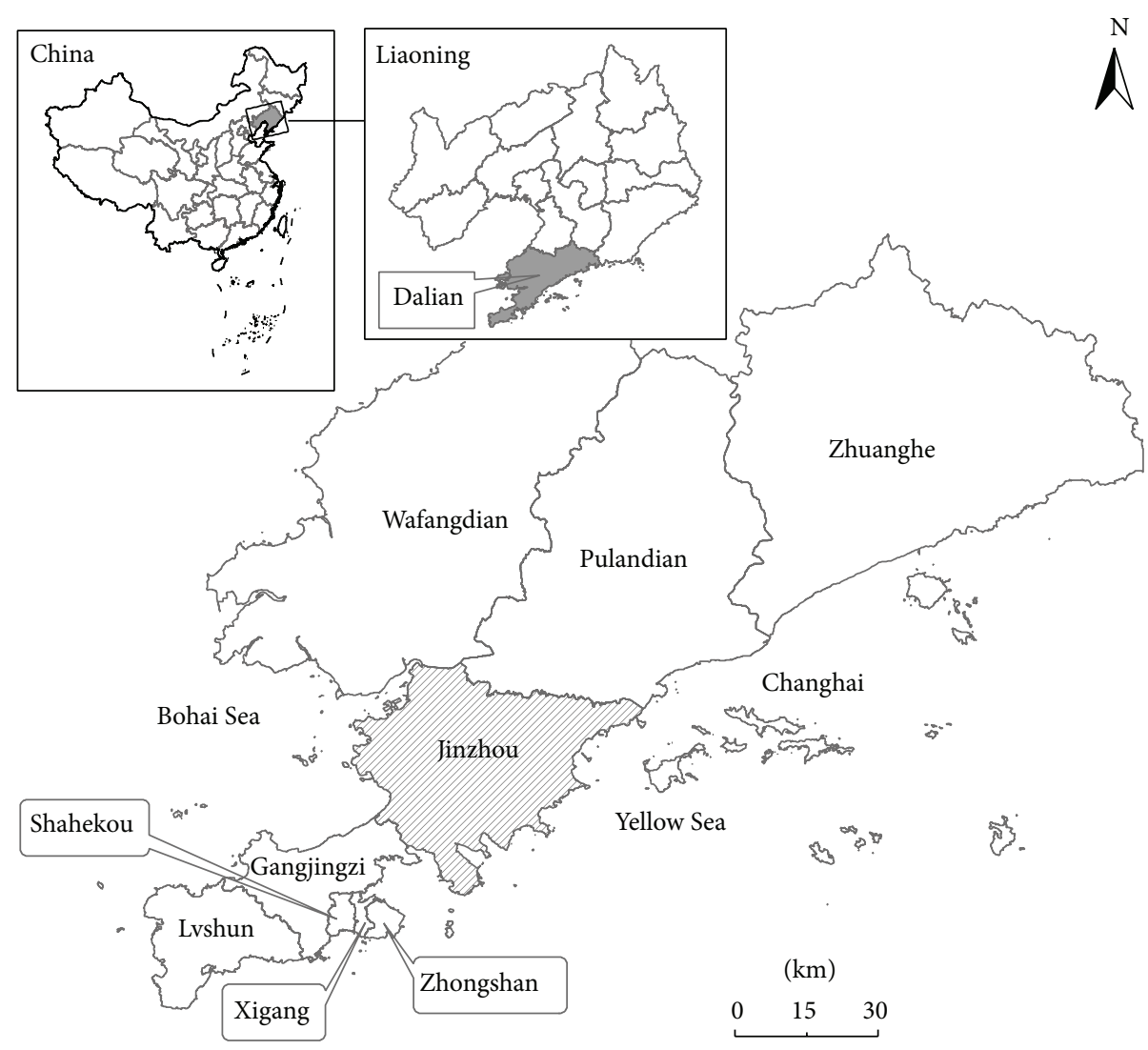

Figure 5: Location of the Jinzhou New District.

TABLE 1: Data sources and description.

\begin{tabular}{lll}
\hline Data type & Data features & Data sources \\
\hline $\begin{array}{l}\text { Land use real maps } \\
\text { Roads }\end{array}$ & $\begin{array}{l}\text { Polygon (1988, 2003, and 2012) } \\
\text { City/town center }\end{array}$ & $\begin{array}{l}\text { Polyline (2012) } \\
\text { Point (2012) } \\
\text { Land use zoning }\end{array}$ \\
Polyline (2012) & Land use planning (2006-2020) & \\
REM & GDeurces and Housing \\
& & $\begin{array}{l}\text { Provided by the International Scientific \& Technical } \\
\text { Data Mirror Site, Computer Network Information } \\
\text { Center, and Chinese Academy of Sciences } \\
\text { (http://www.gscloud.cn) }\end{array}$ \\
\hline
\end{tabular}

change. For example, the construction of roads, highways, and railways will improve accessibility and land transition probability, especially for railways and highways connecting rural areas which can be easily developed; and topography is a main factor restricting agricultural and urban activities, especially in areas with complicated landform characteristics where uneven topography has obstructed urban development and agricultural production. Due to the fact that abundant memory space will be occupied during the simulation, the size of a pixel of present status map of input/output land use and suitability layer of this model is $30 * 30 \mathrm{~m}$. The layer of this spatial resolution can ensure that no memory overflow occurs during the simulation, and relatively accurate simulation result is obtained.

According to Formula (8), in comprehensive consideration of the influences of cities, organic towns, roads, coastlines, and terrain factors on land use change, the simple expression form of the comprehensive suitability of land use is as follows:

$$
\begin{aligned}
L_{i}=( & \beta_{1} d \text { City }+\beta_{2} d \text { Town }+\beta_{3} d \text { Road } \\
& \left.+\beta_{4} d \text { Coastline }+\beta_{5} \text { Slope }\right) \text { Restrict }
\end{aligned}
$$


TABLE 2: Classification of land use types.

\begin{tabular}{ll}
\hline Land use type & Meaning \\
\hline $\begin{array}{l}\text { Agricultural } \\
\text { land (A) }\end{array}$ & $\begin{array}{l}\text { Refers to land directly used for agricultural } \\
\text { production, including cultivated land, garden } \\
\text { land, and grassland. }\end{array}$ \\
\hline & $\begin{array}{l}\text { Refers to the land used for construction of the } \\
\text { buildings and structures, including land for } \\
\text { commercial service, industry, mining, } \\
\text { warehouse, residential, public management, } \\
\text { public service, transportation, and special } \\
\text { demands. }\end{array}$ \\
$\begin{array}{ll}\text { Construction (B) } \\
\text { land }\end{array}$ & $\begin{array}{l}\text { Refers to untapped forests, land less disturbed by } \\
\text { human activity, and other lands except } \\
\text { agricultural and construction land. }\end{array}$ \\
\hline $\begin{array}{l}\text { Unused land } \\
\text { (U) }\end{array}$ & $\begin{array}{l}\text { Refers to the water surface of rivers, lakes, and } \\
\text { reservoirs, tidal flat swamps, and so forth. }\end{array}$ \\
\hline Conservation \\
land (S)
\end{tabular}

TABLE 3: Weights of driving factors.

\begin{tabular}{lcccc}
\hline Driving factors & Meaning & A & B & U \\
\hline dCity & Distance to city center & 0.1045 & 0.2636 & 0.0856 \\
dTown & Distance to town center & 0.3700 & 0.1315 & 0.1253 \\
dRoad & Distance to main road & 0.1641 & 0.4438 & 0.0758 \\
dCoastline & Distance to coastline & 0.0900 & 0.0557 & 0.3380 \\
Slope & Slope & 0.2714 & 0.1054 & 0.3753 \\
\hline
\end{tabular}

where $\beta_{1}, \ldots, \beta_{5}$ refer to the weights acquired from AHP; $d$ City, $d$ Town, $d$ Road, and $d$ Coastline, respectively, indicate the spatial distance scores of city centers, centers of organic towns, roads, and coastlines; Slope refers to slope score; and Restrict refers to the general score of restrictive factors.

The land use suitability layer is generated by using the spatial analysis function of GIS, and the results are normalized (value determined from 0 to 1 ). The method of expert scoring is adopted and AHP is utilized to acquire the weights of the driving factors as the global static decisionmaking basis of each iterative process. The driving factors and their weights selected in this study are shown in Table 3 . The Markov model can effectively predict the amount of change of land use within the time period of simulation. The land use transition probability matrix (Table 4 ) takes the present status maps of land use of 1988, 2003, and 2012 as the initial and final land use types. It is acquired through the method stipulated in 2.1 as the reference in the initial stage of simulation.

\subsection{Simulation Results and Accuracy Evaluation and Analysis.} According to the proportion of each land use type in 2003, transition probability matrix, and the total area of the study area, the land use landscape pattern of the Jinzhou New District in 2012 is simulated with nine years as the step length. Figure 6 indicates the present status map of actual land use of the Jinzhou New District in 2012 (Figure 6(a)) and comparison diagram of simulation results of land use (Figure 6(b)). It is discovered through visual comparison that the simulation results are very similar to the overall pattern of the actual land conditions, thus presenting a high degree of accuracy. The accuracy of the land simulation in the southern

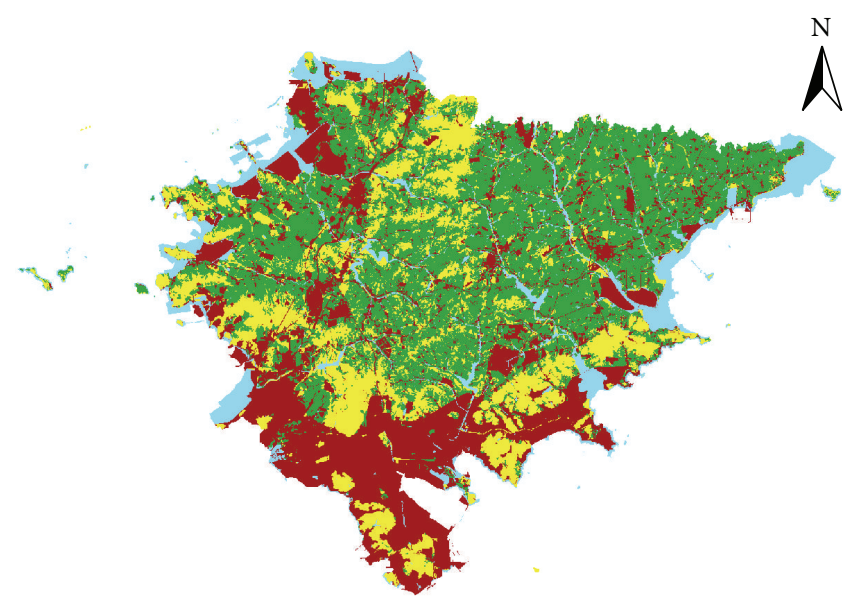

(a) Real map

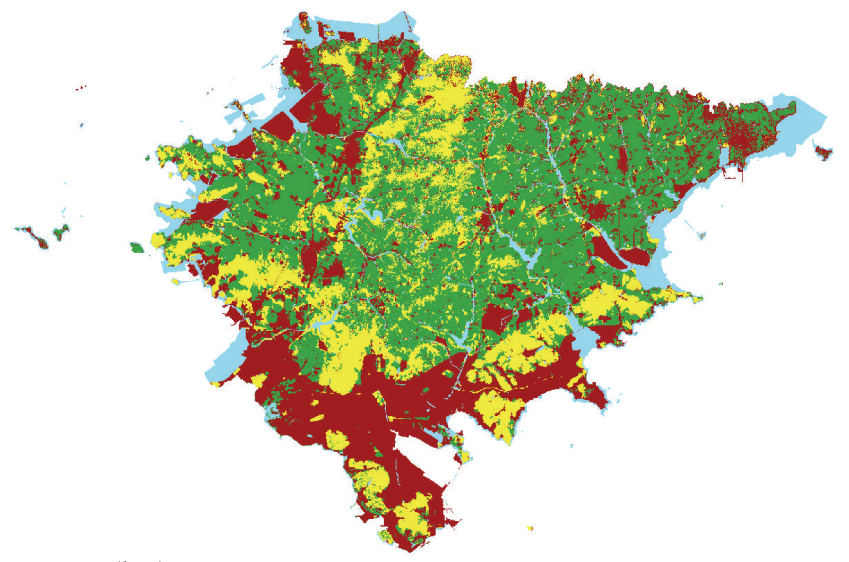

$(\mathrm{km})$

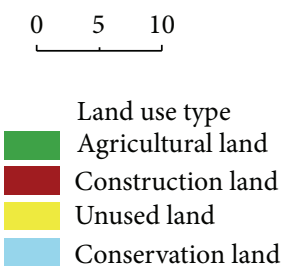

(b) Simulated map

Figure 6: Actual and simulated land use maps of Jinzhou New District.

and western regions is the most outstanding, but the error of simulation result in northwestern and middle regions is relatively significant.

It is discovered from the comparison of this simulation results and real land use map that the distribution of land use of each type indicated in the two images is generally consistent. The area matrix contrast test is shown in Table 5. We can see from the table that the area of each type of land use is of relatively favorable simulation accuracy, of which the conservation land has no change in the process of simulation. The accuracy of the agricultural land area is relatively low, because the degree of advantage of this land use type is relatively low compared with other land use types; it is in a passive changing status and large volatility fluctuation. 
TABLE 4: Transition probability matrix.

\begin{tabular}{lcccc}
\hline \multirow{2}{*}{ Periods of time } & Land use type & \multicolumn{3}{c}{ Transition probability } \\
& & A & B & U \\
\hline \multirow{3}{*}{$1988-2003$} & A & 0.8763 & 0.0528 & 0.0709 \\
& B & 0.0678 & 0.9151 & 0.0171 \\
& U & 0.1049 & 0.0431 & 0.8520 \\
\hline \multirow{3}{*}{$2003-2012$} & A & 0.7483 & 0.1525 & 0.0993 \\
& B & 0.1530 & 0.7722 & 0.0748 \\
& U & 0.2210 & 0.1077 & 0.6713 \\
\hline
\end{tabular}

TABLE 5: Comparison of simulated area and actual area (area unit: $\left.\mathrm{km}^{2}\right)$.

\begin{tabular}{lccc}
\hline Land use type & Simulated area & Actual area & Deviation \\
\hline A & 624.6621 & 636.7995 & -12.1374 \\
B & 408.0852 & 398.2689 & 9.8163 \\
U & 300.5964 & 298.2753 & 2.3211 \\
S & 149.8770 & 149.8770 & 0 \\
\hline
\end{tabular}

In order to improve the accuracy of the follow-up simulation and realize more accurate prediction, it is necessary to conduct an accuracy evaluation of the simulation results. The Kappa coefficient inspection method is the most common quantitative inspection method used to compare the consistency of two images [32]. The higher the Kappa coefficient is, the greater the consistency between the two images will be, that is, higher simulation accuracy. The three tables below (Tables 6, 7, and 8), respectively, indicate the inspection results of the Kappa coefficients of the three land use types, that is, agricultural land, construction land, and unused land. From these tables, we can see that the Kappa coefficients of these three land use types are $0.7269,0.7519$, and 0.7192, respectively, thus presenting a certain level of creditability. Therefore, they can be used to predict the future land use change.

\section{Conclusions and Discussion}

Land use change is a very complicated geographical process. Due to the influence of multiple factors, such as natural conditions, humanistic factors, and social and economic factors, it is very difficult to precisely simulate land use change. Under most circumstances, single-target transition relation among land use types is only considered in traditional land use change models. For example, during the simulation of urban expansion, only the transition from nonurban cells to urban cells is considered, the transition from agricultural land cells to construction land cells, or the transition from unused land cells to construction land cells, that is, one-to-one or multiple-to-one transition. However, the phenomenon of multitarget transition inevitably exists in the actual land use change or urbanization progress (i.e., multiple-to-multiple transition among various land use types). Based on the analysis of the existing land use change simulation model, in comprehensive consideration of the influence of macrodriving factors and local land use competition on land use change and through the coupling of modeling methods such as CA, GIS, AHP, and Markov, this paper has established a multitarget land use change simulation model based on CA and applied it in the simulation of land use change of the Jinzhou New District of Dalian. The method proposed in the paper has improved multiple CA-based models in the past and enabled the CA model to realize the multitarget simultaneous simulation of transition among multiple land use types. The simulation output results depend on the neighborhood effect of cells and the comprehensive driving force of macrodriving factors. The simulation accuracy of the model reaches $72 \%$, thus presenting relatively high creditability. Therefore, it has provided an analyzing and predicting approach for urban land expansion, analysis of land use change driving mechanism of coastal regions, development and protection of unused land like agricultural land and natural reserve, prediction of future development and change trends, and establishment of land resource sustainable utilization policies.

The simulation results of the model are greatly influenced by the model parameters. The setting of the model parameters and the correction of the model have always been a bottleneck for land use change simulation. Land use is the result of interaction between human and nature. Under the comprehensive influence of various natural, social, and economic driving factors, the local land use types are changed as a direct result of change of land use demand and land suitability. Despite the abundant work which has already been performed, the continuity, variation, and functional indexes of the transition rules in different time intervals require further study in the context in which society, economy, and nature drive the land use evolution together, due to their complicated acting relations. However, since the multitarget land use change simulation model established in this paper has only considered the operation of nature, in order to simulate the land use change in a more accurate way, the protected area and planning objective can be embedded as restrictions of the model to simulate possible development models in the research area, so as to evaluate the influence of planning policies on land use change; when setting the weights of the impact factors, the standards can be refined; for example, roads can be refined to different grades of roads such as highways, railways, and provincial roads. In the calculation process, the model occupied large memory space; caching technique needs to be improved. Before making decisions, the planners may use CA to simulate different regional development patterns and select relevant optimum regional development model according to different planning scenarios, so as to provide scientific basis for regional sustainable development and reasonable utilization of land resources.

\section{Conflict of Interests}

The authors declare that there is no conflict of interests regarding the publication of this paper. 
TABLE 6: Kappa coefficient of agricultural land.

\begin{tabular}{|c|c|c|c|c|c|c|c|}
\hline & \multicolumn{4}{|c|}{ Number of pixels } & \multirow{2}{*}{$\begin{array}{l}\text { Observation } \\
\text { consistency }\left(P_{0}\right)\end{array}$} & \multirow{2}{*}{$\begin{array}{l}\text { Expectation } \\
\text { consistency }\left(P_{c}\right)\end{array}$} & \multirow{2}{*}{ Kappa } \\
\hline & $\begin{array}{l}\text { Agricultural } \\
\text { land }\end{array}$ & $\begin{array}{l}\text { Nonagricultural } \\
\text { land }\end{array}$ & Same pixels $(s)$ & Total pixels $(n)$ & & & \\
\hline Actual data & 707555 & 940468 & \multirow{2}{*}{1428003} & \multirow{2}{*}{1648023} & \multirow[t]{2}{*}{0.8665} & \multirow[t]{2}{*}{0.5111} & \multirow[t]{2}{*}{0.7269} \\
\hline Simulated data & 694069 & 953954 & & & & & \\
\hline
\end{tabular}

TABLE 7: Kappa coefficient of construction land.

\begin{tabular}{|c|c|c|c|c|c|c|c|}
\hline & \multicolumn{4}{|c|}{ Number of pixels } & \multirow{2}{*}{$\begin{array}{c}\text { Observation } \\
\text { consistency }\left(P_{0}\right)\end{array}$} & \multirow{2}{*}{$\begin{array}{l}\text { Expectation } \\
\text { consistency }\left(P_{c}\right)\end{array}$} & \multirow{2}{*}{ Kappa } \\
\hline & $\begin{array}{c}\text { Construction } \\
\text { land }\end{array}$ & $\begin{array}{c}\text { Nonconstruction } \\
\text { land }\end{array}$ & Same pixels $(s)$ & Total pixels $(n)$ & & & \\
\hline Actual data & 442521 & 1205502 & \multirow{2}{*}{1486182} & \multirow{2}{*}{1648023} & \multirow{2}{*}{0.9018} & \multirow{2}{*}{0.6041} & \multirow{2}{*}{0.7519} \\
\hline Simulated data & 453428 & 1194595 & & & & & \\
\hline
\end{tabular}

TABLE 8: Kappa coefficient of unused land.

\begin{tabular}{lcccccc}
\hline & & \multicolumn{2}{c}{ Number of pixels } & & Observation & Expectation \\
& Unused land & Used land & Same pixels $(s)$ & Total pixels $(n)$ & consistency $\left(P_{0}\right)$ & Kappa \\
consistency $\left(P_{c}\right)$ & 0.9095 & 0.6777 \\
\hline Actual data & 331417 & 1316606 & 1498922 & 1648023 & 0.7192 \\
\hline Simulated data & 333996 & 1314027 & & & \\
\hline
\end{tabular}

\section{Acknowledgment}

The work described in this paper was substantially supported by the National Support Program of China (no. 2012BAC04B00).

\section{References}

[1] P. Shi, P. Gong, and X. Li, The Methods and Practices on Land Use/Cover Change Research, Science Press, Beijing, China, 2000.

[2] W. Bai and S. Bai, "The status and roles of land use and cover change in global change study," Areal Research and Development, vol. 18, no. 4, pp. 13-16, 1999.

[3] X. Li, "A review of the international researches on land use/land cover change," Acta Geographica Sinica, vol. 51, no. 6, pp. 553$558,1996$.

[4] Q. B. Le, S. J. Park, P. L. G. Vlek, and A. B. Cremers, "LandUse Dynamic Simulator (LUDAS): a multi-agent system model for simulating spatio-temporal dynamics of coupled humanlandscape system. I. Structure and theoretical specification," Ecological Informatics, vol. 3, no. 2, pp. 135-153, 2008.

[5] A. Veldkamp and L. O. Fresco, "CLUE: a conceptual model to study the conversion of land use and its effects," Ecological Modelling, vol. 85, no. 2-3, pp. 253-270, 1996.

[6] Y. Zhang, S. Zhao, and P. H. Verburg, "CLUE-S and its application for simulating temporal and spatial change of land use in Naiman Banner," Journal of Natural Resources, vol. 18, no. 3, pp. 310-318, 2003.

[7] C. He, P. Shi, J. Chen et al., "Research on land use scenario model based on system dynamics model and cellular automata model," Science in China D: Earth Sciences, vol. 35, no. 5, pp. 464-473, 2005.

[8] X. Pei and D. Zhao, "A GIS-SD-based spatiotemporal modelling and regulating policies on water pollution in Dalian gulf," Journal of Remote Sensing, vol. 4, no. 2, pp. 118-124, 2000.
[9] H. S. Moghadam and M. Helbich, "Spatiotemporal urbanization processes in the megacity of Mumbai, India: a Markov chainscellular automata urban growth model," Applied Geography, vol. 40, pp. 140-149, 2013.

[10] Q. Yu, W. Wu, H. Tang, P. Yang, Z. Chen, and Y. Chen, “Complex system theory and agent-based modeling: progresses in land change science," Acta Geographica Sinica, vol. 66, no. 11, pp. 1518-1530, 2011.

[11] B. Qiu and C. Chen, "Land use change simulation model based on MCDM and CA and its application," Acta Geographica Sinica, vol. 63, no. 2, pp. 165-174, 2008.

[12] J. von Neumann and A. W. Burks, Theory of Self-Reproducing Automata, University of Illinois Press, Champaign, Ill, USA, 1966.

[13] X. Li, A. Yeh, X. Liu, and Q. Yang, Geographical Simulation System: Cellular Automata and Multi-Agent System, Science Press, Beijing, China, 2007.

[14] S. Wolfram, "Universality and complexity in cellular automata," Physica D: Nonlinear Phenomena, vol. 10, no. 1-2, pp. 1-35, 1984.

[15] S. Wolfram, A New Kind of Science, Wolfram Media, Champaign, Ill, USA, 2002.

[16] Y. Wang and S. Li, "Simulating multiple class urban landuse/cover changes by RBFN-based CA model," Computers and Geosciences, vol. 37, no. 2, pp. 111-121, 2011.

[17] J. Yang, P. Xie, J. Xi, Q. Ge, X. Li, and F. Kong, "Spatiotemporal simulation of tourist town growth based on the cellular automata model: the case of Sanpo town in Hebei province," Abstract and Applied Analysis, vol. 2013, Article ID 975359, 7 pages, 2013.

[18] J. J. Arsanjani, M. Helbich, W. Kainz, and A. D. Boloorani, "Integration of logistic regression, Markov chain and cellular automata models to simulate urban expansion," International Journal of Applied Earth Observation and Geoinformation, vol. 21, no. 1, pp. 265-275, 2012. 
[19] J. Sun, L. Zhang, C. Peng, Z. Peng, and M. Xu, "CA-based urban land use prediction model: a case study on orange county, Florida, U.S.," Journal of Transportation Systems Engineering and Information Technology, vol. 12, no. 6, pp. 85-118, 2012.

[20] J. Quartieri, N. E. Mastorakis, G. Iannone, and C. Guarnaccia, "A cellular automata model for fire spreading prediction," in Latest Trends on Urban Planning and Transportation, pp. 173$178,2010$.

[21] S. Yassemi, S. Dragićević, and M. Schmidt, "Design and implementation of an integrated GIS-based cellular automata model to characterize forest fire behaviour," Ecological Modelling, vol. 210, no. 1-2, pp. 71-84, 2008.

[22] A. L. Muci, M. A. Jorquera, Á. I. Ávila, Z. Rengel, D. E. Crowley, and M. de la Luz Mora, "A combination of cellular automata and agent-based models for simulating the root surface colonization by bacteria," Ecological Modelling, vol. 247, pp. 1-10, 2012.

[23] J. Yang, Z. Wang, D. Yang, Q. Yang, J. Yan, and M. He, "Ecological risk assessment of genetically modified crops based on cellular automata modeling," Biotechnology Advances, vol. 27, no. 6, pp. 1132-1136, 2009.

[24] Y. Han and S. Ko, "Analysis of a cellular automaton model for car traffic with a junction," Theoretical Computer Science, vol. 450, pp. 54-67, 2012.

[25] M. E. Lrraga and L. Alvarez-Icaza, "Cellular automaton model for traffic flow based on safe driving policies and human reactions," Physica A: Statistical Mechanics and its Applications, vol. 389, no. 23, pp. 5425-5438, 2010.

[26] X. Li and A. G. Yeh, "Neural-network-based cellular automata for realistic and idealized urban simulation," Acta Geographica Sinica, vol. 57, no. 2, pp. 159-166, 2002.

[27] X. Liu, X. Li, Yeh, J. He, and J. Tao, "Intelligent mining conversion rules of geographical cellular automata by using ant colony optimization," Science in China Series D, vol. 37, no. 6, pp. 824-834, 2007.

[28] S. Lauf, D. Haase, P. Hostert, T. Lakes, and B. Kleinschmit, "Uncovering land-use dynamics driven by human decisionmakin - a combined model approach using cellular automata and system dynamics," Environmental Modelling \&Software, vol. 27-28, pp. 71-82, 2012.

[29] P. H. Verburg, T. C. M. de Nijs, J. R. van Eck, H. Visser, and K. de Jong, "A method to analyse neighbourhood characteristics of land use patterns," Computers, Environment and Urban Systems, vol. 28, no. 6, pp. 667-690, 2004.

[30] J. Xu, Mathematical Methods in Contemporary Geography, Higher Education Press, Beijing, China, 2002.

[31] N. Moreno, F. Wang, and D. J. Marceau, "Implementation of a dynamic neighborhood in a land-use vector-based cellular automata model," Computers, Environment \& Urban Systems, vol. 33, no. 1, pp. 44-54, 2009.

[32] J. Cohen, "A coefficient of agreement for nominal scales," Educational and Psychological Measurement, vol. 20, no. 1, pp. 37-46, 1960. 


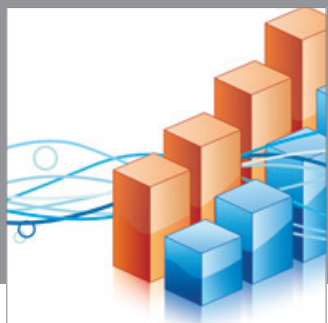

Advances in

Operations Research

mansans

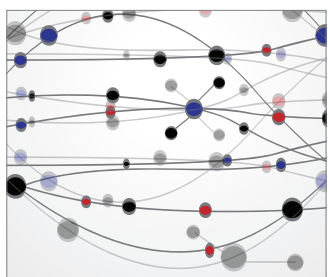

The Scientific World Journal
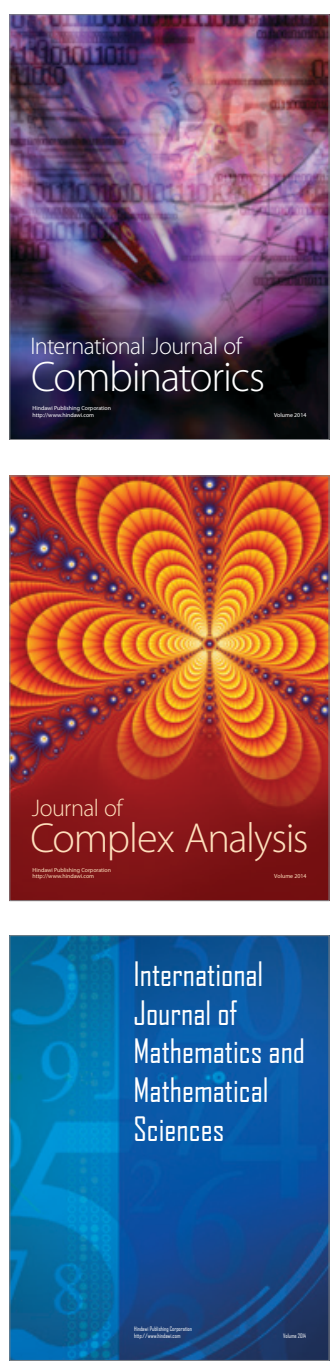
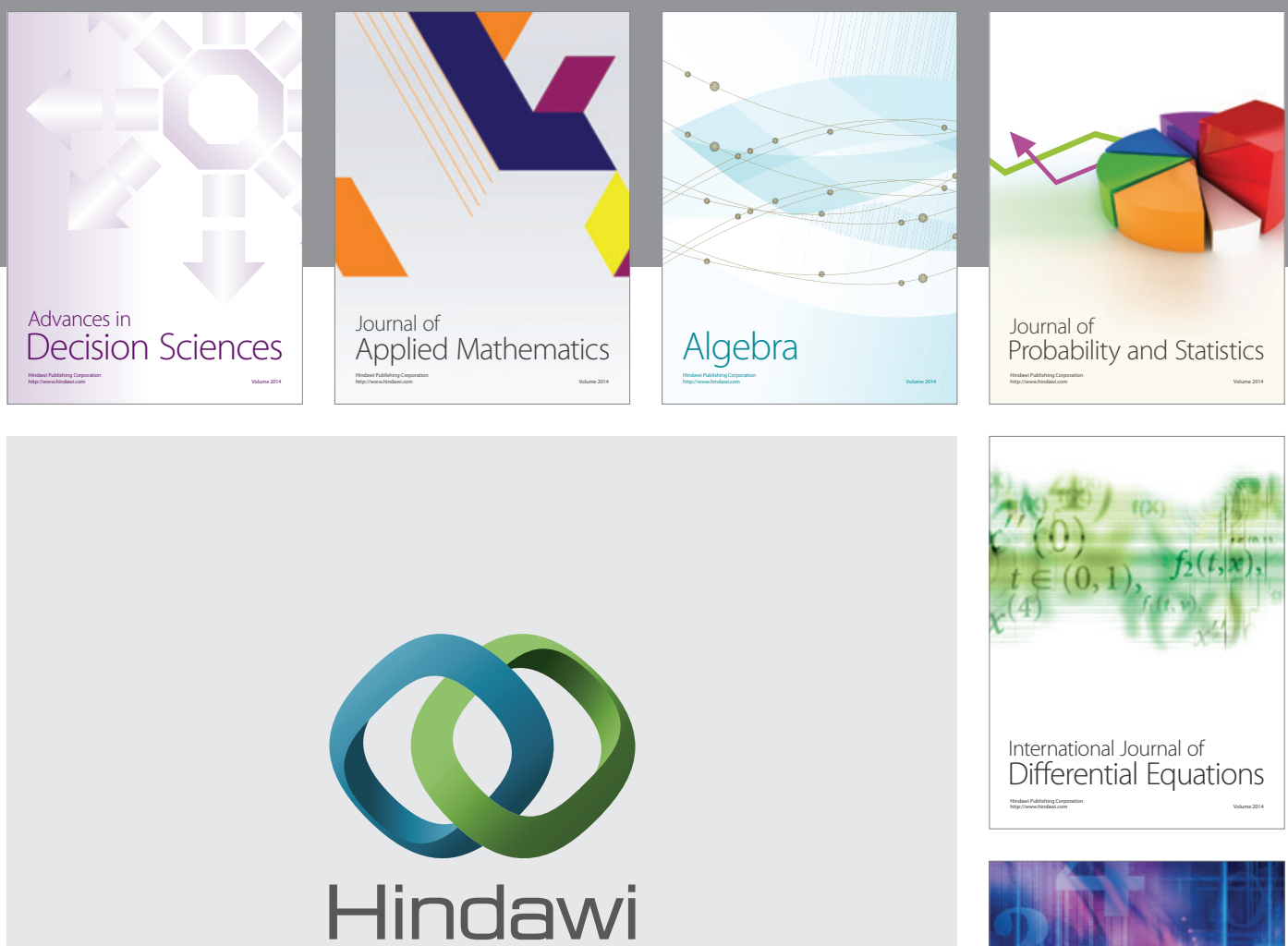

Submit your manuscripts at http://www.hindawi.com
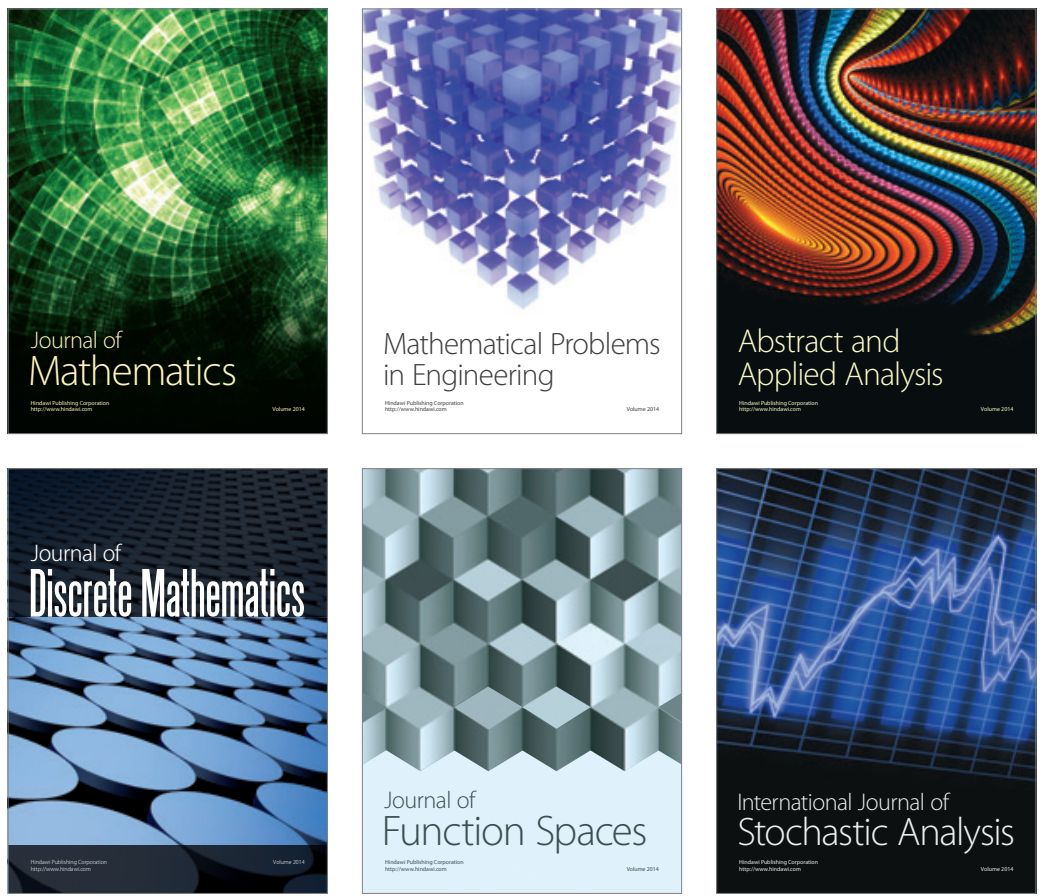

Journal of

Function Spaces

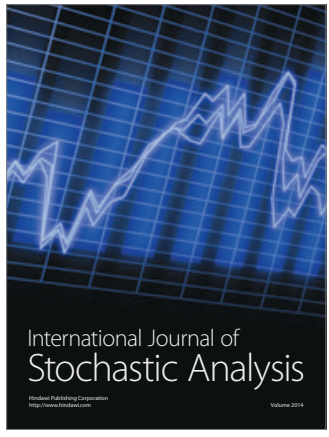

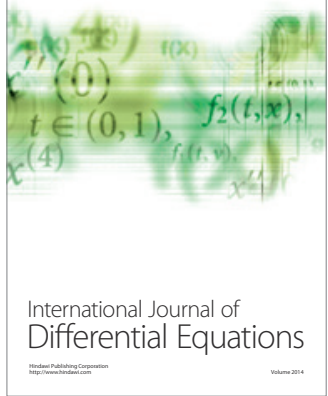
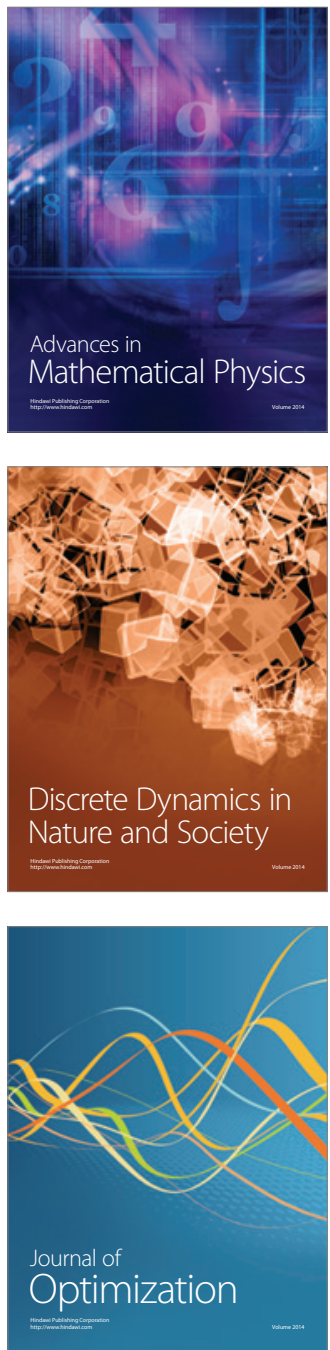